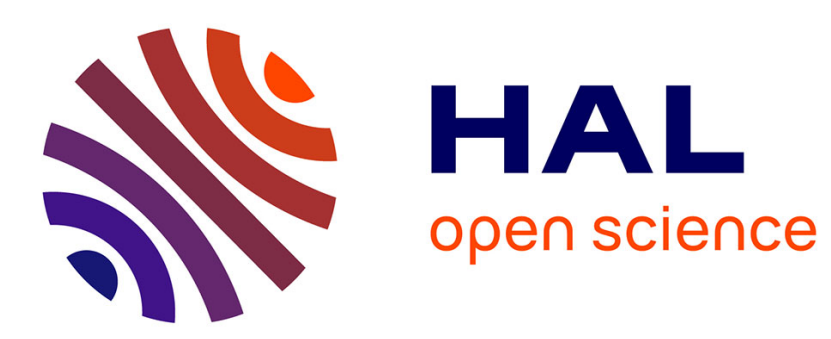

\title{
Defining uncertainty for a simplified method dedicated to the mapping of extreme floods
}

André Paquier, Quentin Royer, Christine Poulard, Pascal Billy

\section{To cite this version:}

André Paquier, Quentin Royer, Christine Poulard, Pascal Billy. Defining uncertainty for a simplified method dedicated to the mapping of extreme floods. Gourbesville, P.; Caignaert, G. Advances in Hydroinformatics, Springer, pp.481-494, 2020, 10.1007/978-981-15-5436-0_38 . hal-03119838

\section{HAL Id: hal-03119838 \\ https://hal.science/hal-03119838}

Submitted on 25 Jan 2021

HAL is a multi-disciplinary open access archive for the deposit and dissemination of scientific research documents, whether they are published or not. The documents may come from teaching and research institutions in France or abroad, or from public or private research centers.
L'archive ouverte pluridisciplinaire $\mathbf{H A L}$, est destinée au dépôt et à la diffusion de documents scientifiques de niveau recherche, publiés ou non, émanant des établissements d'enseignement et de recherche français ou étrangers, des laboratoires publics ou privés. 


\title{
DEFINING UNCERTAINTY FOR A SIMPLIFIED METHOD DEDICATED TO THE MAPPING OF EXTREME FLOODS
}

\author{
André Paquier ${ }^{1}$, Quentin Royer, Christine Poulard \\ Irstea, UR RiverLy, centre de Lyon-Villeurbanne, 5, rue de la Doua, CS 20244, 69625 Villeurbanne, France \\ andre.paquier@irstea.fr, quentin.royer@irstea.fr, christine.poulard@irstea.fr \\ Pascal Billy \\ DREAL Auvergne-Rhône-Alpes, Service Bassin Rhône-Méditerranée Plan Rhône - Pôle Plan Rhône, 69453 Lyon \\ cedex 06, France \\ pascal.billy@developpement-durable.gouv.fr
}

\section{KEY WORDS}

Flood mapping, uncertainty sources, hydraulic calculation, Rhône River, Gardons River.

\begin{abstract}
The risk assessment for extreme floods is a key point to anticipate and to dimension a set of measures to improve the resilience of the territories. Because extreme floods can seldom be observed, the calculation of hazard in the flooded areas comes from an extrapolation of models calibrated on more frequent events. This latter extrapolation can be based on a detailed representation of the processes that may influence the flood features or on a more simplified approach that permits much faster calculations. For the specific cases of the Rhône and Gardons valleys in the Southern France, an estimation of the uncertainty is carried out in order to compare a detailed representation and a simplified approach. called "Additional Depths Method" that guesses the flooded areas of a reference flood are accurately estimated. Then, the topography of the valley above the reference flood level permits to define a set of cross sections in which a uniform flow is calculated for a flow discharge calculated as the difference between the extreme flow and the reference flow. Finally, the limits of the flooded areas are drawn starting from the water elevation interpolated between the values obtained at the cross sections. This simplified approach is encapsulated in a plug-in of the QGIS software. The uncertainty linked to the simplified approach can vary a lot from as low as $10 \%$ up to $100 \%$. The plug-in is convenient in the more favourable cases in which the hypothesis of a ID flow can be kept and the topography agrees with the reference map.
\end{abstract}

\section{INTRODUCTION}

Extreme floods assessment is necessary for flood management. For vulnerable facilities that do not resist to any flooding, it appears as a compulsory requirement. For usual stakes, it is part of the useful data for building a relevant management plan and dimensioning measures for flood damages reduction. Particularly, the 2007 European Flood Directive requires to identify Areas with Potential Significant Flood Risk and map on these areas three levels of floods. In France, the three levels concern [1]:

- a flood between 10 and 30 years return period;

- a flood between 100 and 300 years return period;

1 Corresponding author 
- a flood of at least 1000 years return period.

As such extreme floods are very rare, their hydraulic modelling cannot rely on calibration on floods of equivalent magnitude. Thus, calibration is carried out for more ordinary floods and the calibration is then extrapolated to higher discharges, which means that uncertainty will increase with the flood return period. A recent research project Flowres [2] shows that the use of a relevant model is necessary to reduce the uncertainty generated by the extrapolation. However, even with a well selected and well calibrated model, it is difficult to obtain an accuracy of less than $10 \%$ while the accuracy on the peak flow discharge is typically above $20 \%$ for a 10000 years return period. Then, it is expected that any acceptable hydrodynamic model should be more accurate than this range of $20 \%$.

In France, for more than twenty years, flood hazard has been reported in the PPRI (plans for prevention of flood risks) which relied on the mapping of the 100 years flood or a historical flood if higher. Then, for a lot of rivers, detailed maps of such floods exist and can be considered as a reference of the rare but not extreme floods. One can use the knowledge of the flooding processes contained in these maps in order to build more accurate extreme floods maps. A method was developed to obtain such a map rapidly but the question stands in the uncertainty linked to the simplified method and whether the final map is accurate enough for various purposes.

Here below, after the description of the method, of the software and of the two case studies, the effects of the various factors of uncertainty are estimated.

\section{THE ADDITIONAL DEPTHS METHOD}

\subsection{Description of the method}

The method was named "Additional Depths Method" ("méthode des surcotes" in French language) because it aims at providing the difference between the water elevation accurately calculated for a known flood (typically the 100 years flood), and the water elevation to be estimated for an extreme flood (typically the 1000 years flood).

The method is based on several assumptions. The first one is the one-dimension feature of the flood flow, which can be translated into a calculation of the water elevation in a river cross section. The second assumption is the possibility to calculate the additional depth only from the additional cross section, as if the two flows (respectively below and above the known flood elevation) were separated. The third assumption can be summed up in the use of a Manning Strickler equation (1).

$$
Q=A K_{S} S^{1 / 2} R^{2 / 3}
$$

in which $Q$ is the additional flow discharge, $A$ is the additional wetted area, $S$ the slope, $K_{S}$ the Strickler coefficient and $R$ the hydraulic radius related to the additional wetted area. Energy losses are included in a linear bottom friction, assuming that the influence of the hydraulic structures or other singularities is relatively weak, which can be the case for extreme floods except if there are large structures (bridges or dams generally) that can be considered individually. Because the additional flow is essentially in the flood plain, the Strickler coefficient to be used for calculating additional water depth can be determined from (an average of) the land use of the flood plain (a usual value of $15 \mathrm{~m}^{1 / 3} \mathrm{~s}^{-1}$ is recommended implying additional uncertainty that it is discussed here below). The second important parameter of Eq. 1 is the slope: in case of uniform flow, the energy slope is equal to the bottom slope; to be as close as possible from uniform flow, the slope should be calculated in a homogeneous reach in which the flow is nearly uniform; then, two possibilities exist either the bottom slope or the slope of the free surface for the known flood. If the flow is influenced by a large structure, the slope of the known flood will be obviously a better choice considering that the slope of the known flood is already influenced by the large structure; however, a minimum slope of $0.01 \%$ is requested. The fourth assumption is the decrease of water elevation in the downstream direction; although it seems obvious, 
it is not the best solution to reduce error [3] because such a constraint is likely to accumulate errors if not carried out cautiously; however, it is applied to favour easy interpolation inside one reach and as a factor of control at the junction of two homogeneous reaches.

Three alternatives are selected for the calculation of the additional depth:

1. the more obvious one (called "M2" in the tool) requires to extract the topography of the additional cross sections and solving Eq.1 applying friction on bottom and banks;

2. a simplified version of M2 one (called "M1" in the tool) considers that the additional cross section is a trapeze; it permits avoiding to look for an additional topography that might be finally not representative;

3. using the information about the topography of the main channel if available in order to calculate the water elevation for the whole cross section. The known flood elevation is used to estimate the Strickler coefficient of the known flood area. Then, an average of the Strickler coefficient (between the known flood coefficient and the added flooded area coefficient estimated from land use) is used in Eq.1 (method called "M3" in the tool). In order to calculate the average, the Einstein equation [4] is used (average on the wetted perimeter multiplied by the Strickler coefficient at the power 3/2).

Methods M2 and M3 are using the same topography for the added flooded area and should provide similar results if the topography is accurate; however, in this latter case, method M3 appears to be preferred because it represents the flow resistance in a better way except in the rare cases in which the flow in the added area is separated from the flow for the known flood.

\subsection{Description of the tool}

To permit an easy application of the method, a software was developed in python language and was integrated in Q-Gis as a plug-in called "surcotes" that one can integrate in one's version of QGis in the same way as usual plug-in.

The first step of the tool requires the definition of the following data:

1. A digital topographic model (DTM) that will be used in any case a more detailed topography is not provided (for instance, in France, IGN topographic data basis);

2. The hydraulic axis of the valley (for instance, in France, the BD Carthage hydrographic network);

3. The cross sections that will define the homogeneous reaches (at least two sections for every reach); these cross sections can be defined by two points only if they are straight and if the topography is provided by the DTM; if the topography of the cross sections is known, it could be used instead of the DTM topography which is often less accurate in the main channel;

4. The extent of the know flood as a set of polygons;

5. Eventually the water elevation of the known flood in the cross sections.

The first step of the calculation is the assessment of the Strickler coefficients for the known flood. For M1 and M2 methods, this value is not used but it permits to check that the value of the known water elevation is coherent with the topography of the cross sections. In case the known water elevation is not provided, the user should select one of the values proposed by the software that are coming from the estimate of the elevation of the points in which the boundary of the known flood extent cuts the cross section. In that step, the user can reduce the cross section (if levees or secondary branches not involved in the flow capacity) to match the known flood extent.

The second step of calculation is calculating the extreme flood water elevation by one of the method. Then, this value is used to estimate the extreme flood extent crossing these values at the user 
cross sections and at interpolated cross sections (linear interpolation of water elevation at a constant space step) with the DTM.

\section{THE CASE STUDIES}

\subsection{The Rhône case}

The Rhone case is a 18 kilometres long reach about 50 kilometres downstream from Lyon. The reach was shared in two homogeneous sub-reaches. In the upstream one, the presence of a channel (parallel to the main river and joining it downstream) that is used for hydropower complicates the modelling. However, because the channel is rather narrow if compared to the width of the full flood plain, a simple method to take it into account consists in deducting the full capacity of the channel to the discharge to the flood discharge and compute in the natural topography of the flood plain.

For this reach, the extent of the floods for various return periods were investigated in a detailed way and can be used for references. We will use the 100 years flood as starting and will compare the result of our simplified method for the 1000 years flood with the reference for the same return period. Knowing the discharges for the two return periods and the water elevation for the 100 years return period, we can also compare the water elevations for the 1000 years return period.

A detailed DTM exists in this case but it does not cover fully the extent for the extreme floods. Thus, the procedure was: using the detailed cross sections and DTM to obtain the topography of the cross sections as far as possible and then complete (if necessary) by the $1 \mathrm{~m}$ IGN topographic basis; then using the 1m IGN topographic basis for mapping because it permits to cover the whole area homogenously.

The results show that from the 100 years flood to the 1000 years flood, the flooded area is not strongly increased (for a flow discharge passing from 4970 to $6710 \mathrm{~m}^{3} / \mathrm{s}$ upstream). Figure 1 shows that some discrepancies exist. The three main ones (river main channel, secondary channel for hydropower and flooded area north east of the secondary channel) are only a question of representation; on Figure 1, one can see that the secondary channel can be included or not in the calculation (and thus in the flooded area) depending of the user's choice. The other discrepancies show that the calculation provides nearly always a larger extent of the extreme flood with differences that can be considered as relatively high due to the small differences between the two reference flooded areas. In terms of additional water depth, the result (for the M3 method) is $0.08 \mathrm{~m}$ too high with a mean of the absolute value of the error of $0.2 \mathrm{~m}$ for a mean additional depth of $0.91 \mathrm{~m}$; the relative error ranges from 0 to $98 \%$ with an average of $26 \%$. The discrepancies in the flooded area are coming from a discrepancy between the water elevations provided and the topography used as shown on Figure $2 \mathrm{a}$ on which the map of the 100 years flood extent is drawn from the water elevation and the DTM. Selecting different water elevations for the 100 years flood, on can fit the reference flood extent (Figure 2b) and thus will change also the extreme flood extent and water elevation. For the flood extent, the improvement is verified, particularly, permitting to avoid spurious extensions due to interpolation of water elevations during mapping; however, the differences in water elevation introduced to match the reference flood map are kept for the extreme flood, which means that the calculated extreme water elevations will be wrong reflecting again the discrepancies between the two information (table of water elevation and DTM). 


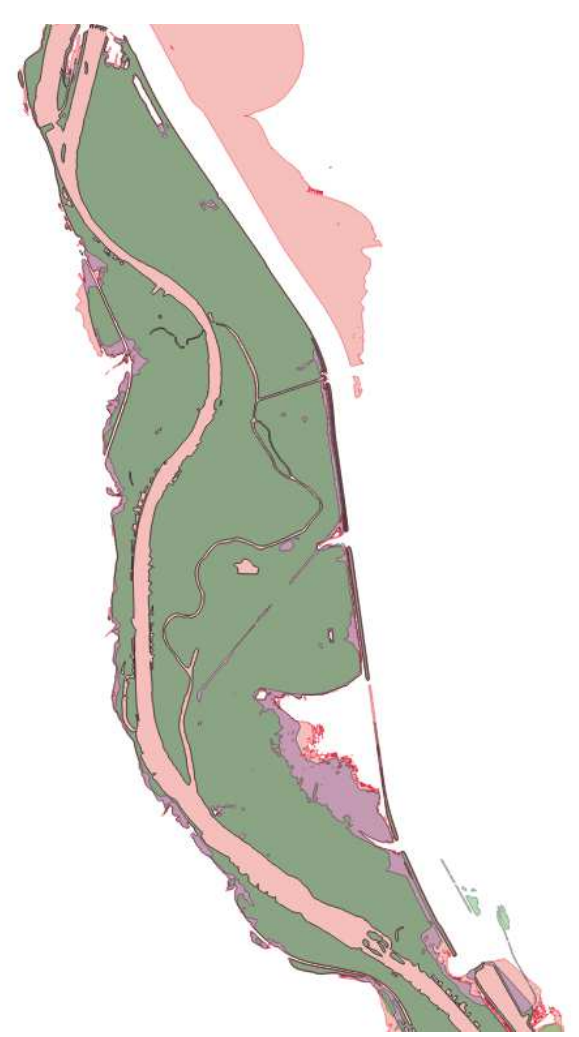

Figure 1: Rhône case - Upstream part of the flooded area (100 years extent with 1000 years extent (reference in violet and calculated in pink)).
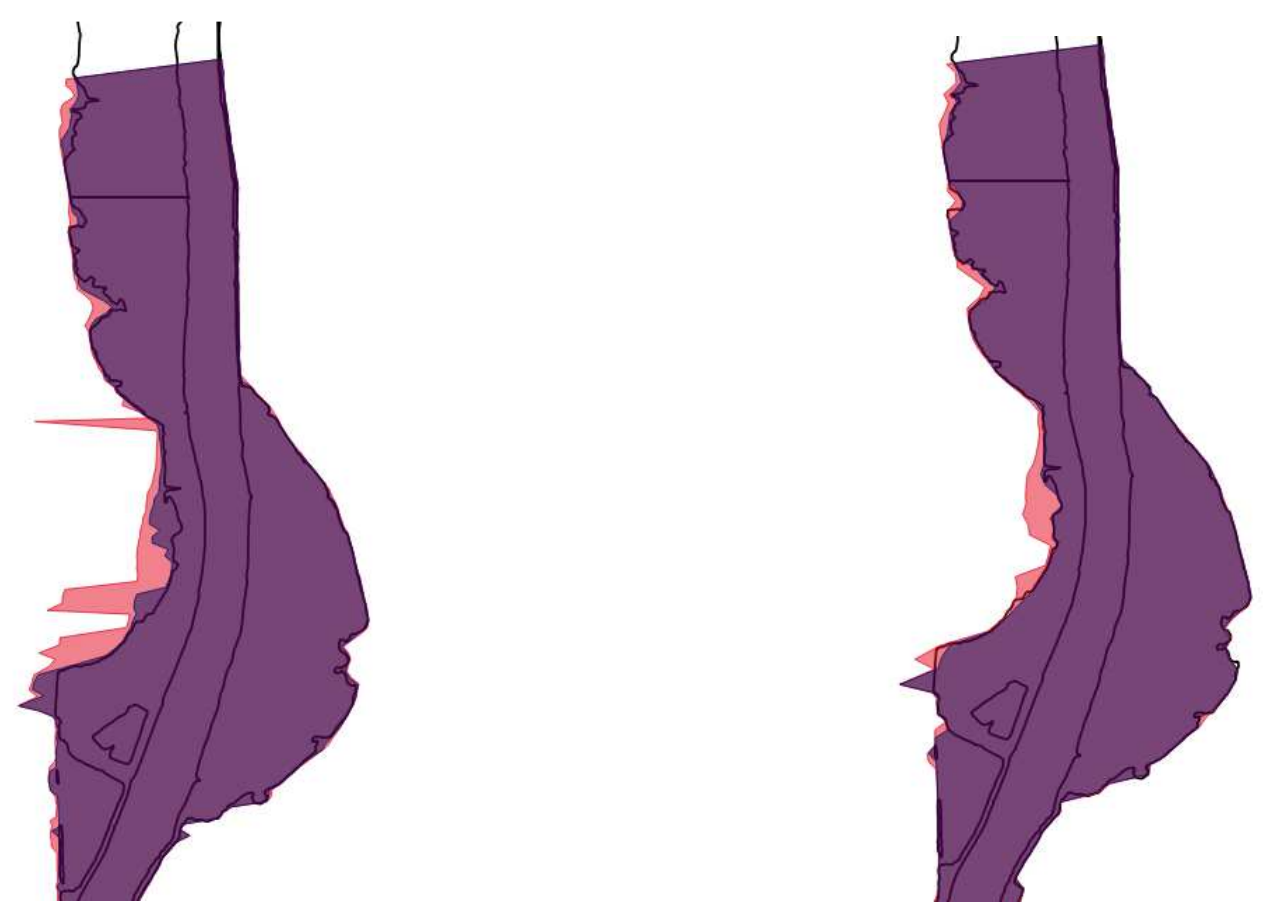

Figure 2: Rhône case - Downstream part of the flooded area: referenced 100 years extent as black line, calculated 100 years and 1000 years extent (respectively in violet and in pink); a (left): initially; b (right): after adjustment of the 100 years extent on the cross sections. 


\subsection{The Gardons case}

The Gardons study area is about 10 kilometres long and includes the city of Alès and the Gardon d'Alès River till it joins the Gardon d'Anduze River. Three sub-reaches were distinguished separated by the confluence of two tributaries. A third tributary in Alès was not fixed as boundary between two sub-reaches but a step in the peak flow discharges was considered. The topography was based on the $5 \mathrm{~m}$ IGN data base and on detailed cross sections that similarly to the Rhone case should be sometimes extended from the $5 \mathrm{~m}$ data base in order to cover the 1000 years flood extent. In that case, there is no reference for the extreme flood extent but the PPRI map can be used as the reference for the known flood. Peak flow discharges were provided for both floods and are used to calculate a reference water elevation at the various cross sections.

Using the 1D model RubarBE [5], several calculations were performed for both peak discharges in order to find some kind of references for the flood extent and water elevations: first with the same sections as the ones used in the tool (called "same" with a standard set of Strickler frictions of 30 $\mathrm{m}^{1 / 3} \mathrm{~s}^{-1}$ in main channel and $15 \mathrm{~m}^{1 / 3} \mathrm{~s}^{-1}$ in flood plain and "KS" with a more varied set of frictions), second with the detailed original sections (called "original" before simplification and extension by the tool, applying the standard set of frictions), third with another set of cross sections that should be more recent (called "other" applying the standard set of frictions). Figures 3 and 4 show that the results obtained are very different. Then, a 2-D model using the software Rubar 20 [6] was also used on the original cross sections and with the standard set of friction coefficients. The differences in water elevation are also important included with the 1D model ("original") with the same topography.

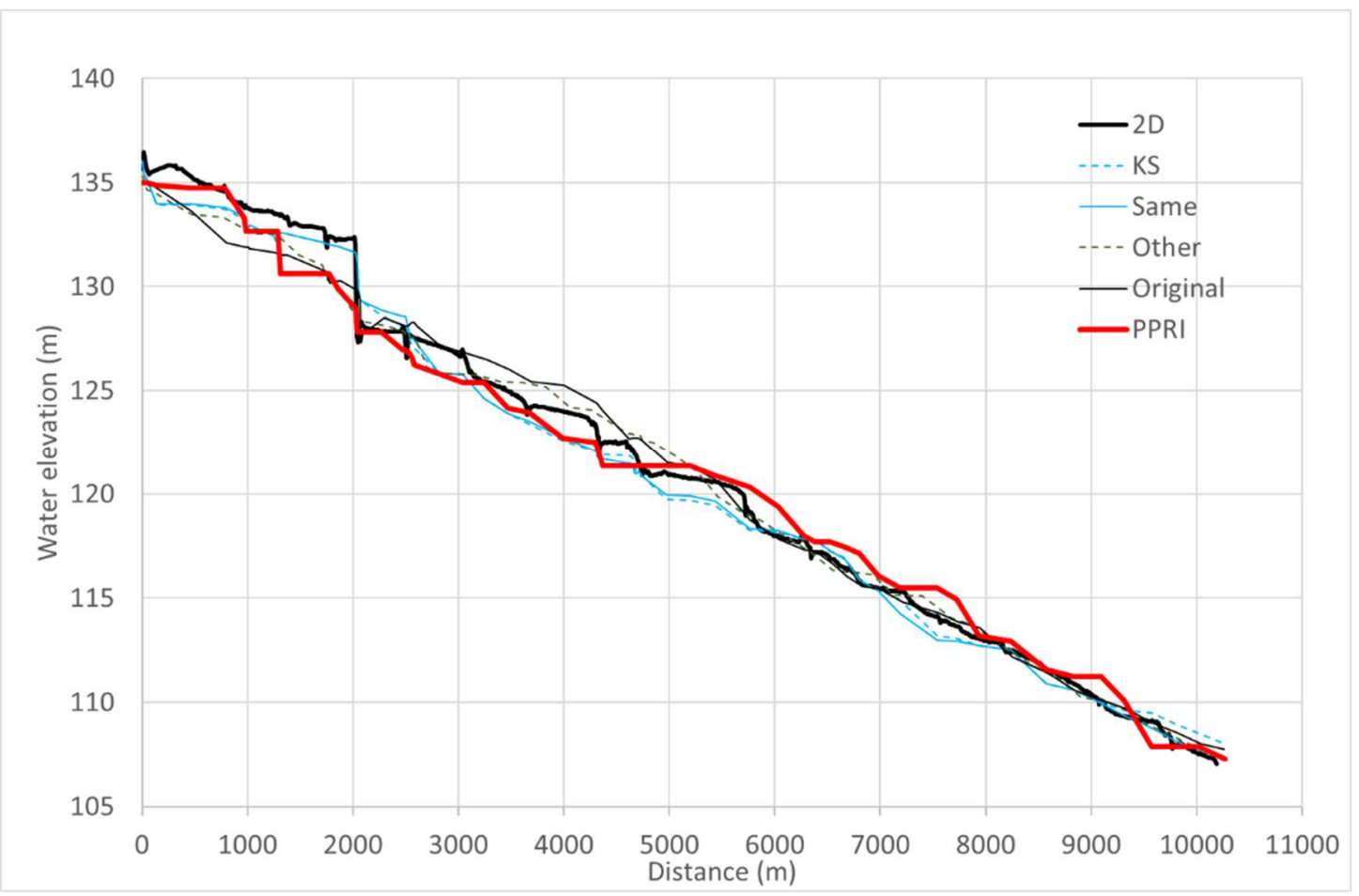

Figure 3: Water elevation along the Gardons reach for the reference flood.

The comparison of the 2D calculation with the reference map (Figure 5) shows also that the 2D model is not well calibrated or that the reference map was not established with the same topography that the one used for our study. Then, it was not surprising that the $2 \mathrm{D}$ model does not provide the same extreme map as the calculation by the additional depths method (Figure 6). On Figure 6, one can see also that even if the water elevations are not exactly the same, M1 (or M2 not shown as nearly identical to M1) and M3 methods provide similar maps except downstream Alès. 


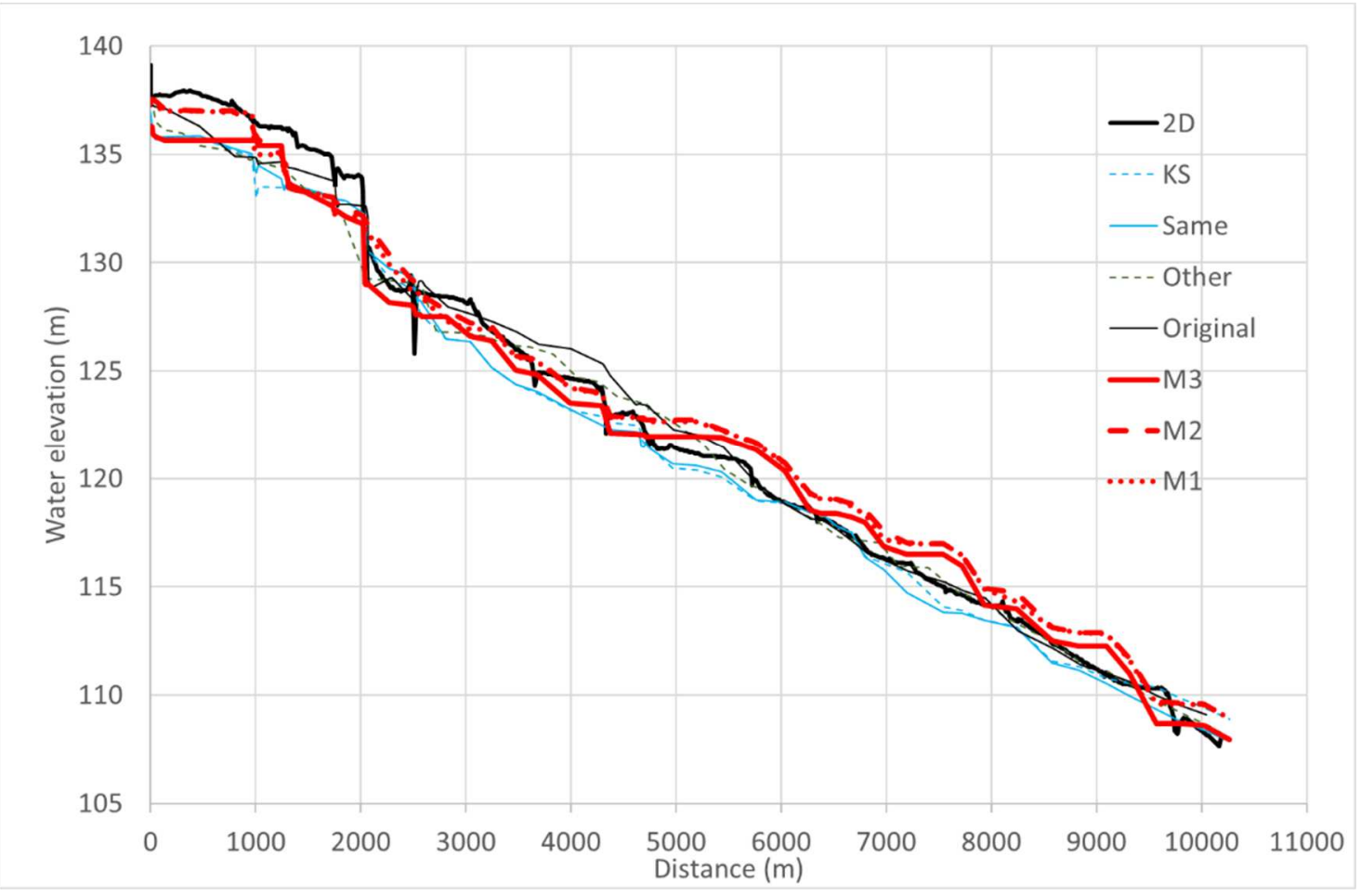

Figure 4: Water elevation along the Gardons reach for the extreme flood.

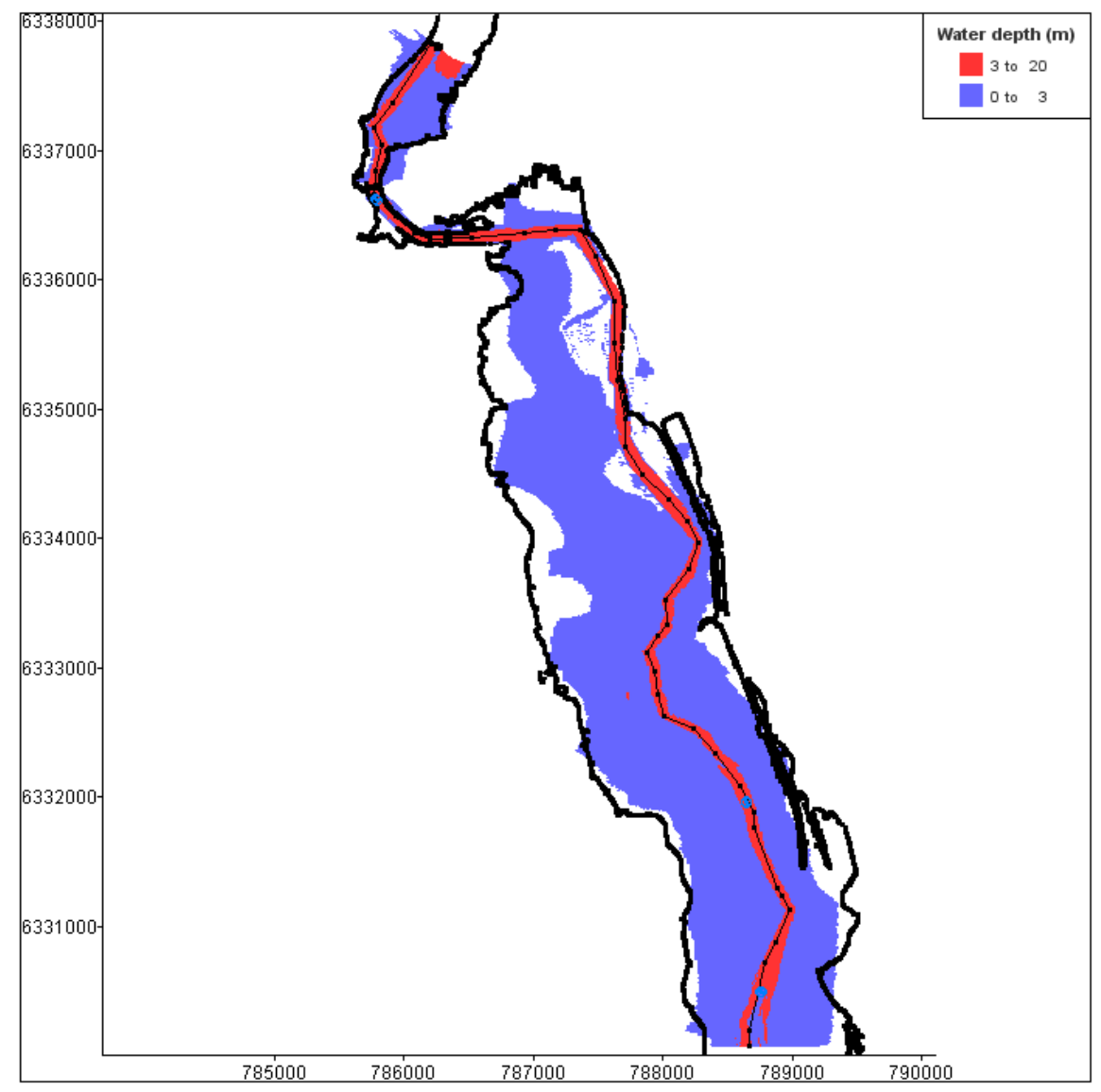

Figure 5: Map of the reference flood calculated using 2D model with the reference extent of the reference flood (black line). 


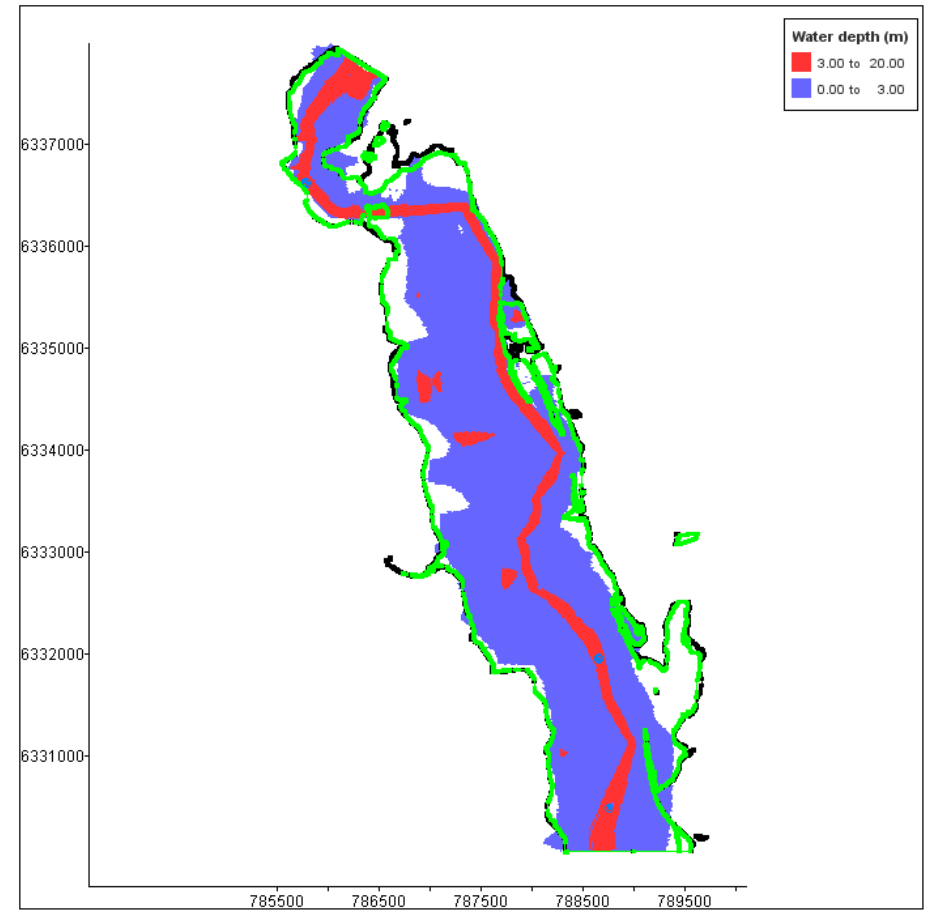

Figure 6: Map of the extreme flood calculated using 2D model with the M1 (black line) and M3 (green line) extent.

Finally, as the tool is only calculating the additional water depths, it is important to evaluate if these additional depths are estimated correctly. Figure 7 shows that except for the first kilometre, M3 method provides an acceptable estimate of the additional water depths, particularly if compared with 2D model results, while it is the opposite for M1 and M2 methods. The narrowing of the flood plain at the crossing of the town of Alès that reduces the free surface slope explains that M3 calculation that keeps the mean slope of the reach (and a uniform flow) provides a too low additional depth (the different geometries enhancing the discrepancy).

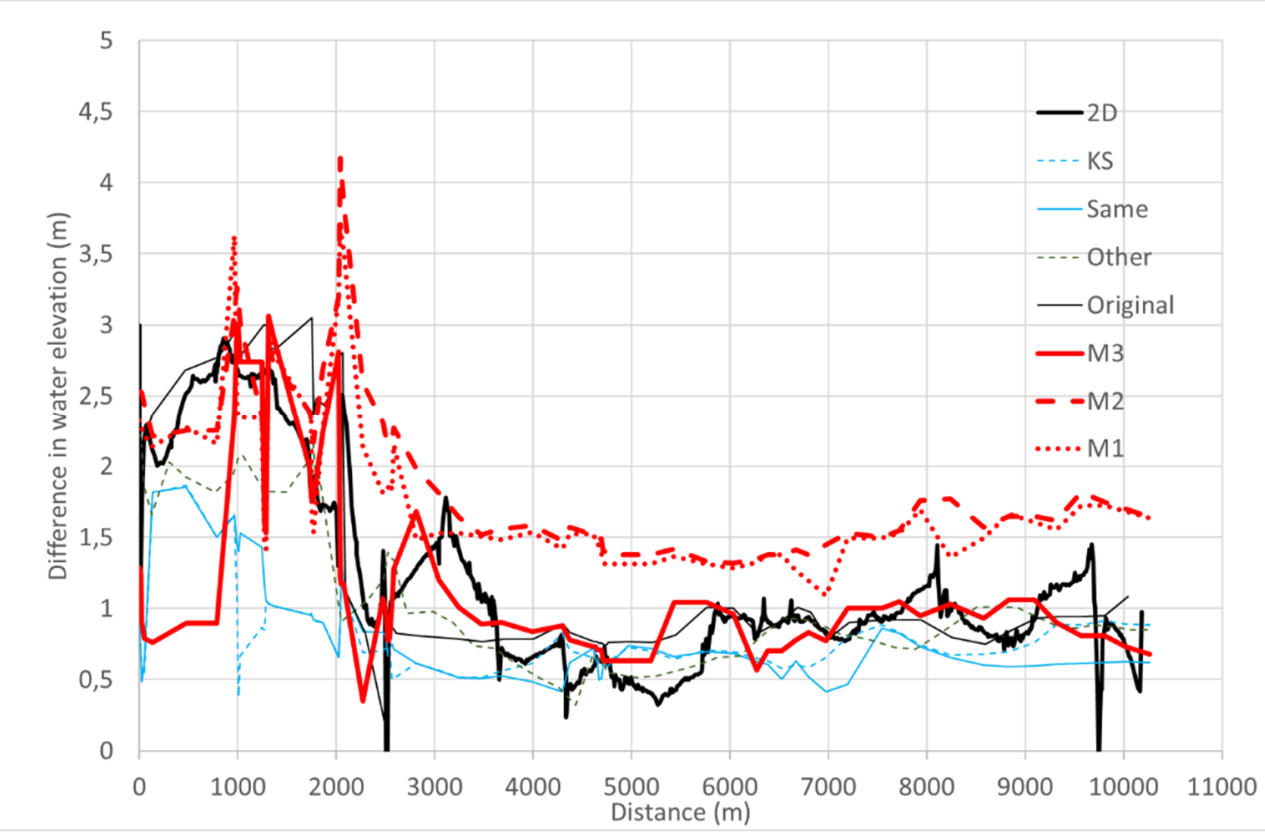

Figure 7: Additional water depths along the Gardons reach between the extreme flood and the reference flood. 


\section{DISCUSSION ABOUT UNCERTAINTY ASSESSMENT}

\subsection{Previous results}

[3] summed up previous studies on the Additional Depths Method. The authors recommended to use the method included in the tool as M3 method except that the constraint of a decreasing water elevation going downstream was not considered as the better solution because, if only one cross section, it may lead to a generalized error on the upstream reach. However, this default can be avoided checking the latter cross section (which is easy in the plugin that indicates the sections on which the correction is modifying the water elevation). On those previous tests, the error on the flooded area (additional flooded areas and erroneously not flooded areas over the total flooded area) was then estimated to about $10 \%$ corresponding to a mean error in water elevations between 1 and 2 metres (about $50 \%$ of the additional water depth). The higher deviations in water elevation were located in narrow valleys with nearly no consequences for flooded areas while the main discrepancies in the flooded area were in the reaches in which the flood plain is very flat (except levees) and thus also places in which the 1-D flow hypothesis can be strongly discussed. The causes of error were identified in the topography, the assessment of the Strickler coefficient in the additional area and the estimate of the slope. However, the main errors were coming from using a local slope and the recommendation was to use a slope at reach scale, either the one of the free surface or the average bottom slope of the valley. The plugin "Surcotes" integrates this recommendation basing the calculation on homogeneous sub-reaches for which the user can define the slope, the default value being the average bottom slope.

\subsection{Uncertainty for the Rhône case}

The default calculation with the method M3 of the plugin provided an error of less than $10 \%$ on the water depths. With M3 method, these results are very stable to changes in friction coefficients and slopes and can be even improved ( $2 \%$ of error) making smoother the topography at the interface of the detailed data and the usual DTM. However, the mapping show large differences with an error of about $70 \%$ in the additional flooded area (if defined as the ratio of the sum of the wrongly flooded area ("not flooded" against "flooded" or "flooded" against "not flooded") to the total flooded area) because the method produces a too large 100 years flood map crossing DTM and reference water elevations. If the 100 years map is corrected by changing the water elevations (average of $0.7 \mathrm{~m}$ necessary), the error in mapping is reduced to about $40 \%$ (and the error in the average additional water depth is about 15\%). This value should be compared to the $30 \%$ increase of the additional flooded area if the 1000 years flow is increased by $10 \%$.

As the topography of the bottom inside the reference flood area is well known, the Rhone case is typically a case in which M1 and even M2 methods should not be recommended. Using them, the error is increased with a rising of water elevation by about $1.2 \mathrm{~m}$ which means an additional flooded area more than doubled. It can be explained that the flow width does not increase a lot leading to a too large friction overestimated at the interface between the 100 years flow and the additional flow.

\subsection{Uncertainty for the Gardons case}

For the Gardons case, no reference for the extreme flood was used. The reference for the 100 years flood shows a flooded area strongly larger than what is obtained by a 2-D model, which reveals a problem of accuracy of the DTM or any other error. The use of various geometries in the 1D model solving de Saint Venant equations shows differences up to 5 metres reminding the importance of an accurate topography for hydrodynamic modelling.

In such a case, only the additional water depths can be compared guessing that similar values will mean a same mapping if one starts from the reference map. The mean increase of the water 
elevation was $1.14 \mathrm{~m}$ for the 2D model and $1.43 \mathrm{~m}$ for the 1D model with the same geometry but only $0.8 \mathrm{~m}$ if the cross sections used in the plugin are used in a 1D de Saint Venant model that generally underestimates the water elevation. The plugin with the M3 method provides an average increase of water elevation of $1.2 \mathrm{~m}$ (1.85 $\mathrm{m}$ for M1 and $2.02 \mathrm{~m}$ for M2), which agrees with 2D model.

However, if the M3 method is further compared to the 2D, the absolute values of the differences in the local additional water depths reach an average of $0.4 \mathrm{~m}$, which means about $30 \%$ of the mean increase of the water elevation; this value reflects the uncertainty that can be expected from the use of the plugin and should be compared to an increase by about $0.6 \mathrm{~m}$ if the flow is increased by $20 \%$ which is a usual uncertainty range for the estimate of a 1000 years discharge. Note that using as reference map, the 2D mapping of the 100 years flood, one provides similar mean increase of water elevation (1.13 m for M3 method) but eventually higher local differences because of the local discrepancies in the topography.

\section{CONCLUSIONS}

The additional depths method guesses that the reference flood map agrees with the topographical data used for extending the flood mapping to the extreme floods. In the two study areas described here above, it was not the case and, thus, it was difficult to evaluate the own accuracy of the method. Because the widening of the flooded area is limited between the reference flood and the extreme flood, the M3 method of the plugin "Surcotes" is the best solution. It can provide a mean additional water depth at less than $10 \%$ but, because locally the difference can be up to $100 \%$, even if the reference map is well reproduced by the plugin, the error in the additional flooded area can be as high as $40 \%$.

Then, it can be recommended to use the plugin "surcotes" only if the flow is mainly 1D and if the DTM used for mapping agrees with the topography used for the establishing the map (the plug in permitting to evaluate that point). Of course, the accuracy of the results will depend on the accuracy of the DTM but also on the selection (by the user) of the more relevant slopes and friction coefficients. The use of the M1 and M2 methods of the plugin should be limited to the cases in which the flooded area increases a lot between the reference and the extreme flood.

\section{ACKNOWLEDGEMENTS}

The development of the "Additional Depths Method" was partly funded by the French Ministry of Environment (MTES).

\section{REFERENCES AND CITATIONS}

[1] Ministère de la Transition Ecologique et Solidaire. Circulaire du 16 juillet 2012 relative à la mise en œuvre de la phase « cartographie » de la directive européenne relative à l'évaluation et à la gestion des risques d'inondation. http://www.bulletin-officiel.developpementdurable.gouv.fr/fiches/BO201214/met_20120014_0100_0044.pdf.

[2] Proust S. et al. (2019). Projet ANR-14-CE03-0010 Flowres. Compte-rendu de fin de projet. Irstea, centre de Lyon-Villeurbanne, France.

[3] Paquier A., Poulard C., \& Faure J.B. (2016). Quick estimate of extreme floods water levels. Proceedings of Floodrisk 2016 conference, Lyon, France.

[4] Einstein H.A. (1934). Der hydraulische oder profil-radius. Schweizerische Bauzeitung, Zurich. 103(8), 89-91. 
[5] El Kadi Abderrezzak K., Paquier A., \& Gay B. (2008). One-dimensional numerical modelling of dam-break waves over movable beds: application to experimental and field cases. Environmental Fluid Mechanics, 8, 169-198.

[6] El Kadi Abderrezzak K., Paquier A., \& Mignot E. (2009). Modelling flash flood propagation in urban areas using a two-dimensional numerical model. Natural Hazards, 50, 433-460. 